\title{
Jerzy Niemczyk
}

Wroclaw University of Economics

e-mail: jerzy.niemczyk@ue.wroc.pl

ORCID: 0000-0002-0766-3929

\section{Rafal Trzaska}

Wroclaw University of Economics

e-mail: rafal.trzaska@ue.wroc.pl

ORCID: 0000-0003-0261-7496

\section{Mateusz Trzaska}

Wroclaw University of Economics

e-mail: mateusz.trzaska@ue.wroc.pl

ORCID: 0000-0003-2901-0280

\section{SCALABILITY 4.0 AS THE MAIN RENT \\ IN INDUSTRY 4.0: THE CASE STUDY OF AMAZON}

\section{SKALOWALNOŚĆ 4.0 \\ JAKO ŹRÓDLO KORZYŚCI W PRZEMYŚLE 4.0. STUDIUM PRZYPADKU FIRMY AMAZON}

DOI: $10.15611 /$ ie.2019.2.05

JEL Classification: M1, M2, M21, M15

Summary: This paper discusses the research problem concerned with identifying the source of the economic efficiency of enterprises operating in the conditions of Industry 4.0. The purpose of this study was to describe scalability 4.0 using the example of Amazon, a global company. In the authors' opinion, it can serve as an example of an organisation which consciously implements a strategy of building value relying on various forms of economies of scale based on contemporary Industry 4.0 technologies. In particular, the authors of this paper point to the capacity to achieve economies of scale, the network effect, the long tail effect, and the Big Data effect by Amazon as a whole and by individual Amazon Group entities.

Keywords: Scalability, Strategic Management, Industry 4.0, Amazon.

Streszczenie: W artykule omówiono problem badawczy związany z identyfikacją źródła efektywności ekonomicznej przedsiębiorstw działających w warunkach Przemysłu 4.0. Celem tego badania było opisanie skalowalności 4.0 na przykładzie globalnej firmy Amazon. Zdaniem autorów może ona służyć jako przykład organizacji, która świadomie realizuje strategię budowania wartości na podstawie różnych form ekonomii skali, opierając się na współczesnych technologiach Przemysłu 4.0. Autorzy artykułu wskazują przede wszystkim na możliwość osiagnięcia korzyści skali, efektu sieci, efektu długiego ogona oraz efektu Big Data zarówno przez Amazon jako całość, jak i przez poszczególne podmioty Grupy Amazon.

Słowa kluczowe: skalowalność, zarządzanie strategiczne, Przemysł 4.0, Amazon. 


\section{Introduction}

Industry 4.0 is a technological, economic, and civilisational revolution of the second decade of the $21^{\text {st }}$ century. Unfortunately, the significance of these transformations is not yet sufficiently reflected in the research conducted in the area of management sciences. It is the studies dedicated to selected Industry 4.0 technologies and their implementation in the activities performed mainly by enterprises operating in the high-tech sector that are most common.

The authors of this paper made an attempt to explain the causes behind the efficiency of Industry 4.0 from the viewpoint of an enterprise from the perspective of the theory of management sciences and the theory of economics. To be precise, the aim of this paper is to present the results of a case study examining Amazon's capacity to generate a Scalability rent composed of: economies of scale and experience curve, the network effect obtained within a network of suppliers, producers and customers, the long tail effect, and the Big Data effect. To this end, they applied the Scalability 4.0 concept presented by a group of authors in the paper entitled "Scalability 4.0 as economic rent in Industry 4.0" (Niemczyk, Trzaska, Borowski, and Karolczak, 2019) as a way of explaining the success of selected Amazon's undertakings. Due to the impossibility to perform the research directly at Amazon, the explanations were made based on reports concerning Amazon and results of the research carried out by other authors, which are available in databases.

\section{Industry 4.0 - the prospects for technological, economic, and management changes}

Industry 4.0 is a technological, economic, and management revolution. It is also a civilisational revolution of the second decade of the $21^{\text {st }}$ century.

Technological changes are related to a set of digital technologies. Among the innovative technologies that constitute the foundation of Industry 4.0, the following are most commonly mentioned: smart sensors, Cloud Computing, digitization, cyber security, mobile devices, blockchain, the Internet of Things, autonomous vehicles, virtual and augmented reality, image recognition, and robotization and automatization.

Economic revolution means changes at the level of economic rents and a radical change (transformation) of business models. Economic revolution is primarily the negation of the classical analysis concerning the choice between the organisation (hierarchy) and the market as the main place of implementing management processes. A brief reference to the role of transaction costs, which is crucial for this choice, should be made here. Progress in the digital economy has made collecting, processing, 
updating, making available, and destroying information considerably easier. As a result, the time of access, number, and quantity of the information required in the contracting processes have become 'friendlier' for the parties trying to reach an agreement. It is worth noting that, on the hierarchy side, the factors reducing costs include the constantly increasing quality of labour resources, automation, and robotization. In such a situation, transaction costs have nearly zeroed, dropped to the level ensured by the hierarchy, yet exclusive of hierarchy costs, and hence, logically, networks and the market have become an efficient solution. In this form, hierarchical solutions are still burdened with hierarchy costs (lower than the prerevolution 4.0 ones), while the market costs are related to very low, yet always existing, transaction costs. This makes even global organisations behave like markets or networks.

The revolution in management systems focuses primarily on the new possibilities of building traditional management tools and generating new business models, which have been unfeasible up to now. The changes are above all changes occurring in logistics processes at the level of customers and suppliers, changes in ways of providing new values to customers, changes in the efficiency of the existing business models and, finally, changes involved in building models using scalability on a mass scale as a tool for managing all organisational processes. The successes of the selected unicorns are evidence of the possibilities.

The civilisational changes, in turn, are first of all the changes arising from the popularisation of new communication systems, and the changes in learning systems. All these changes contribute to the creation of new frameworks for structuring organisational and management activities.

"Each of the mentioned technologies intersects with each other making implementation much more complicated. The idea of Industry 4.0 is based on the ability to optimally use those technologies in order to create business value. Science research can help with constructing the model of economic and managerial dependencies connected with the implementation processes resulting in the shaping of Smart Factories and Smart Companies" (Niemczyk et al., 2019).

\section{Main types of the Scalability 4.0 rent}

The new operating conditions require a new look at the type and method of achieving economic rent.

The Scalability 4.0 rent described in this article is an attempt to define the most important sources of efficiency that can be achieved under Industry 4.0. This is a reference to the classic scalability rent, however, the Conditions of 4.0 and the pressure of the environment resulting from the change of the client's role require that it was not a mass product, but maximally customized (Torn and Vaneker, 2019). 
Technologies 4.0 give this possibility which means conditions for maximally individualized mass production.

In the concept of the article, Scalability 4.0 takes the following form:

1. Economics of scale and experience curve.

2. Network effect obtained within the network of suppliers, producers and customers.

3. Long tail effect.

4. Big Data effect (advantage in data processing and analytics).

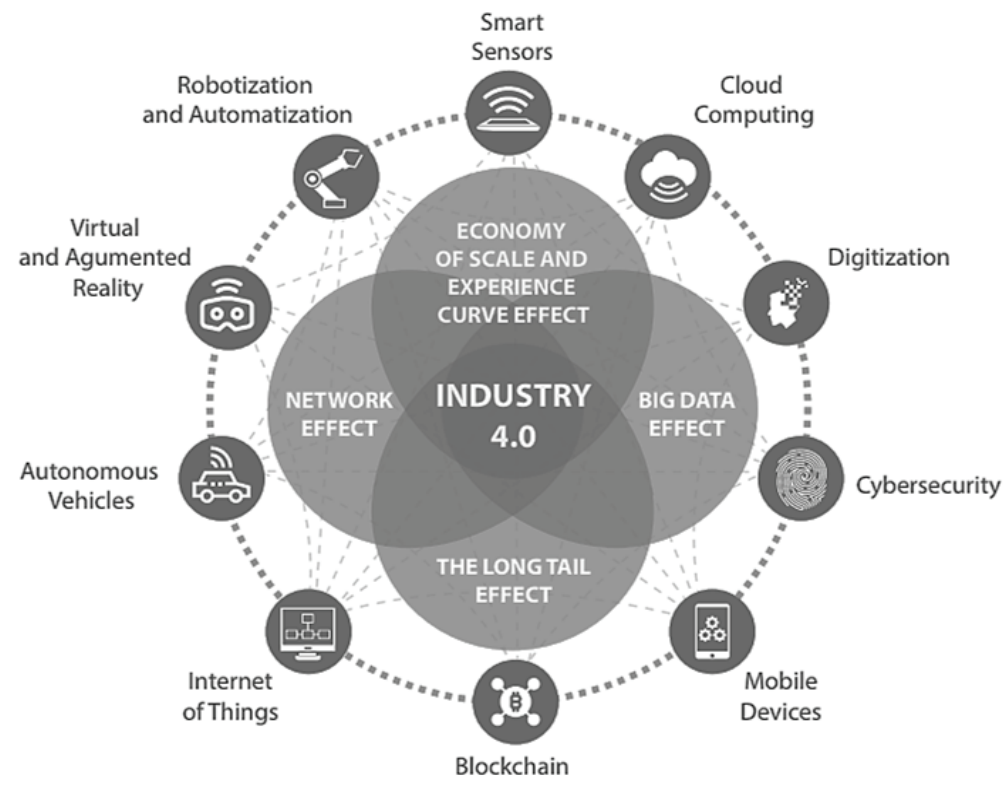

Fig. 1. Scalability 4.0

Source: (Niemczyk et al., 2019).

The first rent is the rent resulting from economies of scale and the curve of experience. Classical mass production in the production process was achieved by standardization and the assembly line. Mass trade was achieved thanks to the concept of large-scale trade also based on the standard. Mass scale in services was possible due to processes. Modern Technologies 4.0 allow to preserve the mass character of production and the individual character of the product.

Operating automation in process management, digitization, the Internet of Things, virtual reality, and smart sensors allow to minimize costs and reduce the time to change the configuration of the production line or process. At the same time, Big Data and Business Intelligence provide the ability to plan, control, and control at zero transaction costs. 
The network effect is also nothing but a combination of economies of scale (increasing number of users) and benefits of scope (using fragments of the experience curve in product creation or service processes) at the already mentioned, highly limited transaction costs.

The network effect is the most network rent of all the network properties. Achieving this effect is only possible in the network. The network effect is the advantage resulting from offering a mass product and service to new groups of clients who are joined as a result of intentional mergers and acquisitions of businesses. This increases the possibility of achieving economies of scale, but more importantly, by increasing the number of customers served, the value of the entire business and the attractiveness of this business offer to existing internal customers increases. This is particularly valuable in businesses which offer products of an intangible character, the service is carried out through a scalable platform and the business model is a subscription model. Amazon, Alibaba, Facebook, Google, and in Poland the Polsat Group, are building their size thanks to the network effect.

The long tail theory is particularly important in businesses where profitability is achieved due to the wide range of products. It occurs at all stages of the value chain. In 2004 Chris Anderson published an article called "The Long Tail". He presented a new concept showing the new rules in modern, online shopping. According to this theory, offering a very wide range of products available for online purchase can generate a total higher turnover on individual, rarely searched products, than those achievable by selling the most popular mass-produced goods (Anderson, 2004). There are three main factors stimulating the Long Tail by causing the reduction of costs of reaching the niches (Anderson, 2006): democratising the tools of production, democratising the tools of distribution and connecting supply and demand.

The long tail is only achievable in conditions of digitization, big data, virtual augmented reality, blockchain, and a whole group of IT tools. Companies whose product range is broad, digitized and offered on a scalable cloud platform achieve a special effect.

The Big Data rent is based on the use of the advantage in processing and data analytics. Information processing improves two basic parameters of the decision making process: it increases knowledge of decision variants, builds new variants and, more importantly, reduces or eliminates the risk in planning, organizing and implementing activities. Big Data gives special effects in marketing. Here, getting to know the market based on the entire data set allows to direct a targeted product offer to the client, suggest other offers, build its value and promote in conditions of individual emotion-based contact (Amado, Cortez, Rita, and Moro, 2018).

The use of these four rents gives the company completely new opportunities to compete. Moreover, in business practice, it allows not only for cost and revenue efficiency, but also for building completely new business models that would be physically impossible under classical economics. 


\section{Formal analysis of Amazon's structure - results of own research}

The article was adopted as the basis for an explanation case study. It includes:

- case selection stage. In the study, due to the innovative nature of the research area, Amazon was chosen. According to the preliminary analysis, it was found that Amazon should meet all the Industry 4.0 assumptions due to its scope of activity and the area of activity.

- Data collection stage. Information for the preparation of the case study was obtained from the company's stock reports, reports of independent consulting companies and white intelligence.

- Data analysis stage. The data analysis focused on selected categories of description coinciding with the analytical scalability model 4.0 adopted in the study.

- Inference stage. Inference in the studied case is a comparison of the obtained test results with the adopted 4.0 scalability analytical model.

The study was conducted in 2019.

The case study of Amazon will be presented in a manner aimed to prove the achievement of the four forms of the Scalability 4.0 rent by the company. This example was chosen intentionally as, in the authors' opinion, its twenty years' history clearly shows the ability to both deal with new technologies and to generate technological changes. A specific characteristics of Amazon is also the ability to monetise the technologies absorbed by the group. The description of the study is composed of five parts:

- Evolution of Amazon's activity in the context of strategy changes;

- Economies of scale and experience curve in Amazon;

- Network effect achieved within the network of suppliers, producers, and customers in Amazon;

- Long tail effect in Amazon;

- Big Data effect in Amazon.

\subsection{Evolution of Amazon's activity in the context of strategy changes}

Amazon is an online retailing company. When it was established, Amazon had a clear mission to become the world's most customer-centric company. Now, over 20 years later this mission remains unchanged. Its strategy is guided by four principles: "customer obsession rather than competitor focus, passion for invention, commitment to operational excellence, and long-term thinking" (Amazon Inc., 2018). Obviously, a strategy formulated in this manner resembles more the organisation's mission than a specific modus operandi. In fact, it should be acknowledged that Amazon's vision is to be the world's most customer-centric company.

The company is divided into three segments: North America, International, and Amazon Web Services, where it offers products and services to consumers, sellers, 
enterprises, developers, and content creators. In 2018 the segment of North America was worth $\$ 141.36$ billion in revenue, the International segment $\$ 65.86$ billion, and the Amazon Web Services segment was only \$25.66 billion (Amazon Inc., 2018). Thus a large portion of the revenue came from North America. International's sales were driven by Amazon Prime, which was a huge success in some of the Asian and European markets, and $11.2 \%$ of the revenue was generated by Amazon Web Services (Amazon Inc., 2018).

Amazon's vision of the business is to "relentlessly focus on customer experience by offering our customers low prices, convenience, and a wide selection of merchandise" (Amazon Inc., 2018).

This is executed by focusing on three main pillars of the company (Amazon Inc., 2018):

1. Amazon Prime: bundled membership with e-commerce, digital content, such as music, video, etc. and free or discounted express shipping;

2. Amazon Web Services: a provider of on-demand cloud services to big consumers;

3. Marketplace: a selling platform for third-parties.

In the 2018 Annual Report, Amazon described its competitive environment as "intensely competitive" (Amazon Inc., 2018). The company identified the following rivals:

- physical, e-commerce, and omnichannel retailers, publishers, vendors, distributors, manufacturers, and producers of the products we offer and sell to consumers and businesses;

- publishers, producers, and distributors of physical, digital, and interactive media of all types and all distribution channels;

- web search engines, comparison shopping websites, social networks, web portals, and other online and app-based means of discovering, using, or acquiring goods and services, either directly or in collaboration with other retailers;

- companies that provide e-commerce services, including website development, advertising, fulfilment, customer service, and payment processing;

- companies that provide fulfilment and logistics services for themselves or for third parties, whether online or offline;

- companies that provide information technology services or products, including on-premises or cloud-based infrastructure and other services;

- companies that design, manufacture, market, or sell consumer electronics, telecommunication, and electronic devices (Amazon Inc., 2018).

As the main competitive factors, they determined (Amazon Inc., 2018) the following:

- consumers: selection, price, and convenience (fast and reliable fulfilment),

- sellers and enterprises: quality, speed, and reliability of services and tools.

The execution of the strategy and its consistency in unchanged values have allowed them to achieve a milestone of $\$ 1,000$ billion in market capitalisation. 
Amazon's strategy can be viewed from the perspective of various strategy approaches. In the classical, strongly historical one, as regards the growth strategies adapted by Amazon, they can be categorised with the use of the Ansoff matrix. The tool provides four growth strategies: market penetration, market development, product development, and diversification (Ansoff, 1957). Amazon's primary growth strategy is market development. This strategy focuses on the entry to and growth in new markets. The company has been expanding its geographical presence since its beginning. Nowadays it is the world's biggest e-commerce company operating in 58 countries with population reach of over 1.2 billion people (O'Brien, 2018). The objective of this growth strategy is to establish a retail website in a given country's local language. This allows the company to attract new people as part of its global market reach. Amazon's second growth strategy is market penetration. Its aim is to generate more revenue where the company currently operates. Amazon's growth is correlated with increasing consumerism. As consumers are more interested in online shopping, the company benefits from higher sales revenues (Smithson, 2017). The objective of this growth strategy is to penetrate the market by attracting consumers through aggressive marketing campaigns and low prices. As an auxiliary growth strategy, Amazon applies Product Development, which is supposed to develop and offer new products in order to increase revenue. The company continually introduces new products, e.g. Amazon Basics products, Amazon Web Services, and IoT appliances. The final growth strategy adopted by Amazon is Diversification. This approach concentrates on growth based on new businesses. As was mentioned earlier, Amazon not only acts as an online retailer, but also offers web services and digital content. Moreover, the company's acquisition activity helps it grow and expand to new markets (for instance, the acquisition of Audible, an audiobook company, and Twitch, an e-sport streaming website (CB Insights, 2018). The aim of this strategy is to develop an e-commerce business through an aggressive acquisition strategy (Smithson, 2017). The perspective of the classical Ansoff strategy shows Amazon's capacities to generate economic surplus from economies of scale and economies of scope. In the opinion of the authors of this paper, this does not allow a complete understanding of the logic behind Amazon's development. Such a thinking is too narrow and does not permit Amazon's rapid development in the late 2010s to be fully understood. The only significant element is the already mentioned economies of scale, to which the authors refer in the next part of the case study.

According to the positioning approach represented by M. Porter, Amazon's business strategy can be summarised by the generic strategies concept created by him in 1985. He suggested that companies needed to choose to offer products for a broad market or a narrow one (a niche market) and adopt a differentiation or cost leadership strategy (Porter, 2004). As stated by Porter, a company can select only one direction. However, Amazon's case shows that a mix of cost leadership and a differentiation strategy can prove practicable. Thanks to massive warehousing facilities and processing capabilities, the company achieves economies of scale. 
Moreover, advanced computing and network technologies allow better process automatization. This translates into lower costs of purchase processing, scheduling, and other operations of Amazon's online retail services, while the use of technology benefits the differentiation strategy. Its online platform permits the company to offer a wide range of products. Another differentiating factor is Amazon Prime membership, which enables free or discounted express shipping and gives access to digital content, such as videos, music, etc. Moreover, there is excellent customer service, for which Amazon is famous. According to the positioning approach, the strategy is related to monopolistic rent, which is not pointed out by the quoted authors. However, it seems that this is the rent obtained by Amazon. The company is the leader in many markets, thus effectively driving up profit margins.

As regards the resource approach of the strategy, concentration on Amazon's key competence, arising from managing the e-commerce platform operating globally, is worth emphasizing. Amazon successfully uses this competence, at the same time continuously seeking new ones. The significance of the brand assets should also be stressed (the value of the Amazon brand is $\$ 315.5$ million according to Brand Finance). In 2019 it was the most valuable brand in the world. Other valuable Amazon's assets include relationships, patents, and licences.

According to the innovative approach, Amazon must be considered the retail sector leader. It is also the leader in other sectors, which it established on its own. It is the ability to operate in the blue ocean area that makes competitors lag behind Amazon. Such innovations creating new operation areas included Amazon Associates, Amazon DevPay, Amazon Mechanical Turk, Amazon SimpleDB, Alexa Site Thumbnail, and Alexa Web Search, etc.

The final theoretical approach to the strategy is the network one. Since it is a part of the Scalability concept adopted in this paper, it is only signaled here.

The indicated general characteristics of Amazon's strategy, as viewed from various perspectives, do not allow a comprehensive answer to the question about the essence of Amazon's strategy. The phenomenon of the strategy and the type of the economic rent obtained currently by the company require a different, multidimensional, look at the activities of this retail market giant.

\section{Main types of the Scalability 4.0 rent using the example of Amazon}

\subsection{Economies of scale and experience curve - the case study of Amazon}

Amazon puts emphasis on improving its logistics and fulfilment. The company expanded its warehouse facilities by 1,210\% over 10 years (Amazon Inc., 2018). In 2012 it acquired Kiva Systems, a company which designs and manufactures mobile robots used for order fulfilment in distribution warehouses. Kiva helped cut operating costs in fulfilment centres by $20 \%$ (Business Insider, 2016). 
Economies of scale occur when the increase in revenue does not imply linear growth in operating costs.

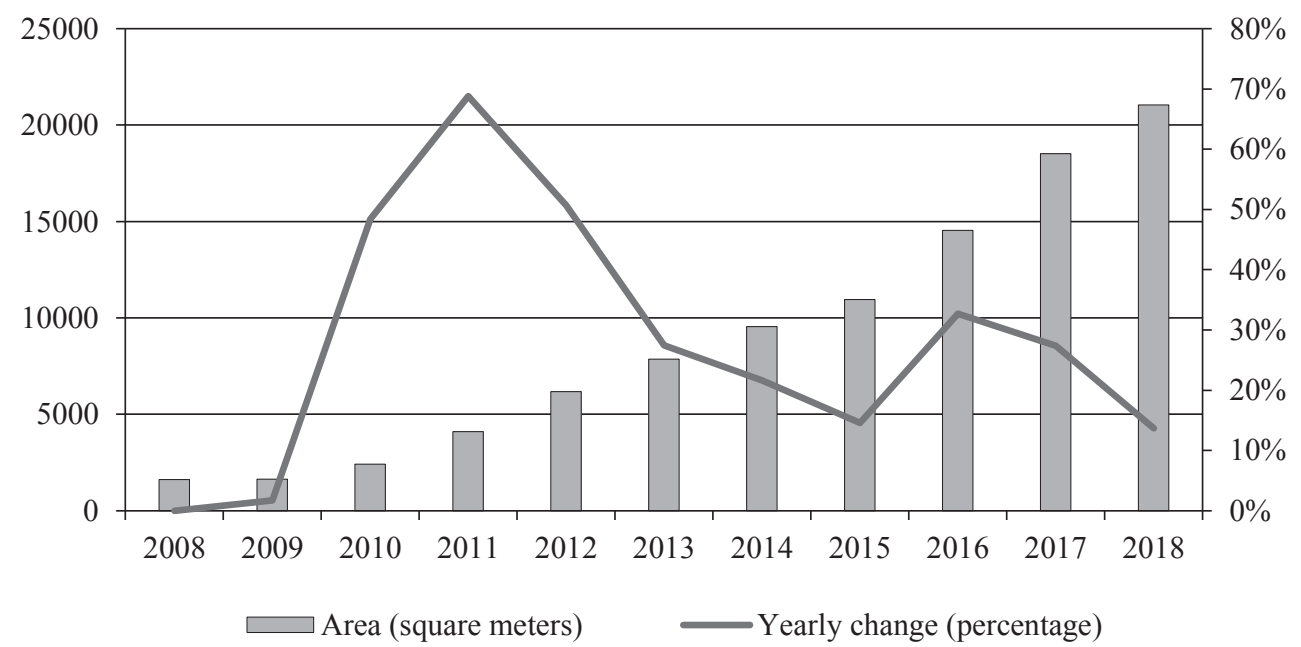

Fig. 2. Growth in the area related to Amazon's activity in the period 2008-2018

Source: Amazon's annual reports (2009-2019).

Table 1. Amazon's financial information 2008-2012

\begin{tabular}{|l|r|r|r|c|c|}
\hline \multicolumn{1}{|c|}{ million USD } & \multicolumn{1}{c|}{2008} & 2009 & 2010 & 2011 & 2012 \\
\hline Net Sales & 19166 & 24509 & 34204 & 48077 & 61093 \\
\hline Cost of Sales & 14896 & 18978 & 26651 & 37288 & 45971 \\
\hline Operating expenses & 3428 & 4402 & 5813 & 9370 & 13613 \\
\hline Operating expenses change y/y & $18 \%$ & $18 \%$ & $17 \%$ & $19 \%$ & $22 \%$ \\
\hline Fulfillment & 1658 & 2052 & 2808 & 4443 & 6207 \\
\hline Marketing & 482 & 680 & 1002 & 1591 & 2347 \\
\hline Technology and content & 1033 & 1240 & 1511 & 2617 & 4130 \\
\hline G\&A & 279 & 328 & 386 & 565 & 770 \\
\hline Other & -24 & 102 & 106 & 154 & 159 \\
\hline
\end{tabular}

Source: Amazon's annual reports (2009-2013).

Developing a massive distribution network and investing in technology did not bring an increase in profits. This implies no economies of scale effect according to the traditional definition. However, in the conditions of Industry 4.0, the meaning of economies of scale is broader than financial values, it is when the company offers new values based on existing solutions.

Amazon's goal is to reduce the time needed to deliver goods, provide exceptional customer service, and at the same time try to reduce the costs associated with delivery. 
Table 2. Amazon's financial information 2013-2018

\begin{tabular}{|l|r|r|r|r|r|r|}
\hline \multicolumn{1}{|c|}{ million USD } & \multicolumn{1}{c|}{2013} & \multicolumn{1}{c|}{2014} & \multicolumn{1}{c|}{2015} & \multicolumn{1}{c|}{2016} & \multicolumn{1}{c|}{2017} & \multicolumn{1}{c|}{2018} \\
\hline Net Sales & 74452 & 88988 & 100700 & 135987 & 177866 & 232887 \\
\hline Cost of Sales & 54181 & 62752 & 71651 & 88265 & 111934 & 139156 \\
\hline Operating expenses & 18392 & 24561 & 33122 & 43536 & 61826 & 81310 \\
\hline Operating expenses change y/y & \multicolumn{1}{c|}{$25 \%$} & \multicolumn{1}{c|}{$28 \%$} & \multicolumn{1}{c|}{$33 \%$} & \multicolumn{1}{c|}{$32 \%$} & \multicolumn{1}{c|}{$35 \%$} & \multicolumn{1}{c|}{$35 \%$} \\
\hline Fulfillment & 8291 & 10391 & 13410 & 17619 & 25249 & 34027 \\
\hline Marketing & 3045 & 4207 & 5254 & 7233 & 10069 & 13814 \\
\hline Technology and content & 5962 & 8471 & 12540 & 16085 & 22620 & 28837 \\
\hline G\&A & 980 & 1359 & 1747 & 2432 & 3674 & 4336 \\
\hline Other & 114 & 133 & 171 & 167 & 214 & 296 \\
\hline
\end{tabular}

Source: Amazon's annual reports (2014-2019).

In order to achieve this, it is crucial to develop a fulfilment centre network resembling a spider's web around the world. Within the traditional meaning of economies of scale, the expansion of Amazon's distribution capacity should have helped the company reduce operating costs. This is not the case for Amazon as its costs increased from around 18\% of sales in 2008 (Amazon Inc., 2009) to 35\% of net revenue in 2018. It is worth stressing that the costs have remained at the level of around $35 \%$ since 2015. Despite that, Amazon obtains rent from economies of scale and experience curve in conditions of Industry 4.0 because it is the reduction of shipping times and the increase in customer satisfaction that adds value for customers. This is ensured by Amazon Prime membership: "Subscribers automatically defer to shopping at Amazon first because they know shipping is free and fast, due to express service. Amazon covers all the shipping on Prime orders" (Krämer and Kalka, 2017). The analysis of 2011 showed that Prime users spent $\$ 35$ on digital content and \$55 on shipping. This means that Amazon lost $\$ 11$ per member annually (the Amazon Prime membership costs \$79) (Tuttle, 2013). However, customer loyalty increased and revenue grew more than 11 times over a ten-year period (from \$19 billion in 2018 to $\$ 234$ billion in 2018). This is the execution of Amazon's clear vision to trade off short term benefits against long-term cash flows. "Its key strategy is to be able to capture the largest market share and scale possible that will allow it to drive down costs and increase profitability in the future." (Krämer and Kalka, 2017).

Moreover, Amazon's R\&D investments are included into the "Technology and Content" item of financial statements, which also increases operating expenses. Some R\&D projects are related to improving fulfilment and logistics, such as the Airborne Fulfilment Centre, an airship that serves as a distribution centre for autonomous drones which deliver goods to customers (Amazon Technologies Inc., 2014).

A subscription model, such as Prime Membership, allows to obtain additional rent through economies of scale. One of the key elements of this service is access to an 
unlimited amount of digital content provided by Amazon (i.e. music, movies). As Amazon has an increasing number of users, the cost of producing their own digital content is spread across a larger customer base. Additionally, this type of service is characterized by the fixed cost of providing the service, which is the platform maintenance costs (fixed). The result is a reduction in the unit costs of individual digital content when more subscribers register for the service and achieve economies of scale.

\subsection{Network effect - the case study of Amazon}

Rent from the network effect can be obtained by acquiring other customers or groups of customers in order to offer them the company's product or service and increase the value provided to the existing customers. This can be achieved by M\&A activities. It is easiest to achieve the network effect in enterprises such as Amazon by taking over customer bases. This leads to a higher number of conducted transactions and at the same time to the increased attractiveness of the entire company for the existing customer base. The effect is even better when a supplier network that is compatible with Amazon is purchased together with the customer base. In such a situation, Amazon achieves enhanced economies of scale by offering the existing sale platform and distribution channels to new customer communities. The network effect can be achieved also by offering Amazon's platforms, supplier, environment relationship, marketing, etc. management systems. The enumerated methods of extending the customer base can be best obtained through mergers and acquisitions. Obviously, Amazon does that also through internal development in new markets. The distribution network growth dynamics are impressive in this case.

Internal development can be illustrated by acquisitions. Amazon's growth is driven by acquisitions: it spent more than $\$ 20$ billion on its top ten acquisitions reflecting diverse business interests: e-commerce, media and content, robotics, IoT, hardware, and healthcare (CB Insights, 2019).

The biggest Amazon M\&A deal amounted to $\$ 13.7$ billion. Whole Foods, a grocery chain, was acquired in 2017. As a result, Amazon immediately included grocery products in its product portfolio and expanded its operations.

There are some other benefits of that acquisition. Amazon's vast consumer data set has been generated by the 450 physical locations of Whole Foods. This will help Amazon in expanding its online grocery business and private label offerings. Moreover, Prime Membership has created a new customer base as the shipping method is provided via this service. The mix of the online and offline shopping experience gives Amazon more insight into how the same person shops in this channel, which implies better targeting.

Another example of obtaining rent from the network effect is Amazon's acquisition of Souq.com, Amazon's Dubai-based competitor for the Middle East. This enabled the company to enter into a new market and take over the already established strong customer base as Souq claimed over 45 million visitors per month 
and a range of 8.4 million products across 31 categories. The region covers around 50 million customers and only around $2 \%$ of online shops (Russel, 2017).

Activities in this area must be intensive since Amazon's main competitor, China's Alibaba, can achieve economies of scale practically in its own market without changing or modifying its business models. In fact, this is what it did in the period 2015-2019.

\subsection{Long Tail effect - the case study of Amazon}

The authors of this paper define rent from the long tail effect as the value generated by the company on individual, rarely searched products instead of on selling the most popular mass-produced goods. There is some evidence saying that this is not possible.

Amazon, as an online platform, focuses on selling standardised products, but its marketplace services (a platform that enables third-party sellers to sell products) generate the long tail effect. This means that Amazon only focuses on selling and fulfilling high-demand products, bestsellers in each categories, and leaves long-tail merchandise for its third-party entities (Voigt, 2017). For example, in the electronic category, Amazon sells only $7 \%$ of products, while the remaining $93 \%$ is distributed by independent sellers (Baojun Jiang, 2011). Due to the lowest possible variety of products, Amazon relies on a heterogeneous group of renowned brands and no-name sellers (Voigt, 2017). This approach is beneficial in many ways, for example a wide range of products, from popular to most niche ones, attract customers and push them to buy many different goods in one place. Despite a lower margin on niche products, they are still present and ensure the necessary insight to Amazon. Moreover, Amazon, as a global company, cannot know niche markets as they are not scalable. Niche sellers know their customers better and have better access to niche suppliers, which implies lower risks and costs of the long-tail sale. The advantage for Amazon is that the company receives revenue anyway; in this case, it is a fee on each transaction. The next benefit is that all costs and risks associated with selling niche products are passed onto third-party sellers. Lastly, Amazon uses long-tail effect data for market research because it tracks which products sell better and become the mainstream goods.

\subsection{Big Data effect - the case study of Amazon}

The Big Data effect is generated in three main categories:

1. Revenue generation.

2. Cost optimisation.

3. Services expansion.

The company generates extra revenue using Big Data bases algorithms, such as Personalised Recommendation System (CFE), and Book Recommendations from 
Kindle highlighting. CFE analyses the items a customer purchased previously, what is on the wish list, in a cart, what the customer has reviewed, and recommends additional products to buy. The book recommendation system was created as a result of the acquisition of Goodreads, a social network platform with over 25 million users, who are connected with their Kindle devices. Based on highlights and notes made in e-books, Amazon reviews words to determine what customers are interested in and recommend other books based on preferences. Amazon's recommendation system engines delivered over 35\% of all sales (Goff, 2015).

Amazon obtains rent from the Big Data effect through cost optimisation. It does this by using an anticipatory shipping model, which uses big data for predicting the products that a particular customer is likely to purchase within a particular time and the products customers may need in different locations. The items are sent to local distribution centres and will be ready for immediate shipment when the customer orders a given product. The constant flow of products through the distribution network was achieved by the right-time communication with Amazon's stakeholders (Davenport, 2006). Predictive analytics helps it optimise costs and provide better customer service by faster shipping. Using the Big Data system, Amazon can optimise its whole supply chain, from manufacturing to delivering. Algorithms for choosing the warehouses that are closest to the vendor and customer reduce shipping costs by $10 \%-40 \%$ (Willis, 2018).

The final category is service expansion. The development of Amazon's own Big Data solutions caused the emergence of new products that are open to all customers, i.e. Amazon Web Services. This is the cloud computing service that enables companies to create scalable Big Data applications and secure them without having hardware or maintaining infrastructure on their own. "Big Data applications like clickstream analytics, data warehousing, recommendation engines, fraud detection, event-driven ETL, and the Internet-of-Things (IoT) processing are through cloudbased computing" (Willis, 2018).

It appears that this area is among those with the greatest development potential. The increase in the number of customers will probably become slower and slower, especially in the circumstances of growing competition. In such a situation, the knowledge of Big Data can help Amazon create an ecosystem composed of the customers who will be supplied with new groups of products, which have not been offered before. This enables the construction of a service system where the barriers to exit are high enough to discourage customers from leaving the ecosystem. Such activities have already been undertaken in the US and UK markets.

\section{Conclusion}

The Scalability 4.0 concept is a common phenomenon but not fully recognized. It relies on the rent related to economies of scale and experience curve. In the opinion of the authors of the paper, there are already many organisations using this type of 
scalability. One of the best examples is Amazon. Jeff Bezos, when building Amazon, probably did not think of all these solutions that are characteristic of the contemporary business models. However, he certainly had a vision of a global company. Being consistent in building his experience, he succeeded by designing a scalable business, which was effectively tested in the initial years of its operation. Thus, he avoided the mistake of a too fast territorial development of the company, which might not have been able to cope with the technological development.

The indicated examples of scalability confirm that Amazon consciously builds its strategy by using economies of scale and experience curve, the network effect achieved within the network of suppliers, producers and customers, the long tail effect, and the Big Data effect.

On the other hand, a weakness of the management theory is the too slow examination of this type of organisations for the purpose of understanding the real mechanisms of such concepts and building on such knowledge, which increases the epistemological level of management sciences. The authors of this paper used primarily the knowledge generated in other disciplines of science and papers on management, which provide a preliminary presentation of the possibilities of using the four effects as a uniform organisation's operation system.

\section{References}

Amado, A., Cortez, P., Rita, P., and Moro, S. (2018). Research trends on Big Data in marketing: A text mining and topic modeling based literature analysis. European Research on Management and Business Economics, (24), 1-7.

Amazon Inc. (2009). Amazon Inc Annual Report 2008. Retrieved August 20, 2019 from https://ir.aboutamazon.com/static-files/e1846da7-9425-42d9-add7-84218d7ee5e7

Amazon Inc. (2010). Amazon Inc Annual Report 2009. Retrieved August 20, 2019 from https://ir.aboutamazon.com/static-files/f793debb-dc0a-4edf-a56d-9ff739d53b41

Amazon Inc. (2011). Amazon Inc Annual Report 2010. Retrieved August 20, 2019 from, https://ir.aboutamazon.com/static-files/6f3c99ed-5094-4fed-a9ad-e18cdbf37478

Amazon Inc. (2012). Amazon Inc Annual Report 2011. Retrieved August 20, 2019 from https://ir.aboutamazon.com/static-files/02a49fbe-6860-4ed7-ade4-905bcf16a5e1

Amazon Inc. (2013). Amazon Inc Annual Report 2012. Retrieved August 20, 2019 from https://ir.aboutamazon.com/static-files/28bfea7a-7b18-4ab0-ba03-581c6ccaa3a4

Amazon Inc. (2014). Amazon Inc Annual Report 2013. Retrieved August 20, 2019 from https://ir.aboutamazon.com/static-files/1be0475a-fcab-4826-9258-17f11c208487

Amazon Inc. (2015). Amazon Inc Annual Report 2014. Retrieved August 20, 2019 from https://ir.aboutamazon.com/static-files/d6263104-b6fa-401a-aa29-3b66ec713f76

Amazon Inc. (2016). Amazon Inc Annual Report 2015. Retrieved August 20, 2019 from https://ir.aboutamazon.com/static-files/fdf51af3-79e0-4b3c-9868-19aa75aa0306

Amazon Inc. (2016). 2015 Letter to Shareholders. Retrieved August 20, 2019 from https://ir.aboutamazon.com/static-files/f124548c-5d0b-41a6-a670-d85bb191fcec

Amazon Inc. (2017). Amazon Inc Annual Report 2016. Retrieved August 20, 2019 from https://ir.aboutamazon.com/static-files/380785a4-779c-4252-897b-539d3ef70680 
Amazon Inc. (2018). Amazon Inc Annual Report 2017. Retrieved August 20, 2019 from https://ir.aboutamazon.com/static-files/917130c5-e6bf-4790-a7bc-cc43ac7fb30a

Amazon Inc. (2019). Amazon Annual Report 2018. Retrieved August 20, 2019 from https://ir.aboutamazon.com/static-files/0f9e36b1-7e1e-4b52-be17-145dc9d8b5ec

Amazon Technologies Inc. (2014). Google Patents. Retrieved August 20, 2019 from https://patents. google.com/patent/US9305280B1/en

Anderson, Ch. (2004). The long tail. Retrieved July 27, 2019 from https://www.wired.com/2004/10/ tail/

Anderson, Ch. (2006). The long tail. Why the future of Business is selling less of more (pp. 52-57). New York: Hyperion.

Ansoff, I. (1957). Strategies for diversification. Harvard Business Review, 84(5), 113-124.

Baojun Jiang, K. J. (2011). Firm strategies in the "mid tail" of platform-based retailing. Marketing Science, (10), 757-944.

Business Insider. (2016). Kiva robots save money for Amazon. Retrieved August 20, 2019 from https:// businessinsider.com.pl/kiva-robots-save-money-for-amazon-2016-6

CB Insights. (2018). Amazon strategy teardown. Retrieved August 20, 2019 from https://www.cbinsights.com/research/report/amazon-strategy-teardown/

CB Insights. (2019). Amazon biggest acquisitions infographic. Retrieved August 20, 2019 from https:// www.cbinsights.com/research/amazon-biggest-acquisitions-infographic/

Davenport, T. H. (2006). Competing on analytics. Harvard Business Review, 84(1), 98-107.

Goff, J. M. P. (2015). Need for speed: Algorithmic marketing and customer data overload. McKinsey Quarterly, (3).

Krämer, A., and Kalka, A. R. (2017). How digital disruption changes pricing strategies and price models. In Phantom ex machina (pp. 87-103). Switzerland: International Publishing.

Niemczyk, J., Trzaska, R., Borowski, K., Karolczak, P. (2019). Scalability 4.0 as economic rent in industry 4.0. Transformations in Business \& Economics (in print).

O’Brien, F. (2018). Website builder expert. Retrieved August 20, 2019 from https://www.websitebuilderexpert.com/ecommerce-website-builders/age-of-ecommerce-empires/

Porter, M. E. (2004). Competitive Advantage. New York: Free Press.

Russel, J. (2017). Amazon completes its acquisition of Middle Eastern e-commerce firm Souq. TechCrunch. Retrieved August 21, 2019 from https://techcrunch.com/2017/07/03/amazon-souq-com-completed/?guccounter=1\&guce_referrer_us=aHR0cHM6Ly93d3cuZ29vZ2x1LmNvbS8\&guce_referrer_cs $=$ fXNdgWHdJII5Mo7ZRIOhxQ

Smithson, N. (2017). Amazon.com Inc. generic strategy and intensive growth strategies. Panmore Institute. Retrieved August 20, 2019 from http://panmore.com/amazon-com-inc-generic-strategyintensive-growth-strategies

Torn, I. A. R., Vaneker, T. H. J. (2019). Mass Personalization with Industry 4.0 by SMEs: A concept for collaborative networks. Procedia Manufacturing, (28).

Tuttle, B., (2013). Amazon prime loses $\$ 11$ annually per member ... and it's a huge success. Time. Retrieved August 22, 2019 from http://business.time.com/2011/11/14/amazon-prime-loses-11annually-per-member-and-its-a-huge-success/

Voigt, K. -I. B. (2017). Creating the global shopping mall: The case of Amazon. In Business model pioneers, management for professionals (pp. 67-77). Switzerland: Springer International Publishing.

Willis, J. (2018). 7 ways Amazon uses big data to stalk you. Investopedia. Retrieved August 21, 2019 from https://www.investopedia.com/articles/insights/090716/7-ways-amazon-uses-big-data-stalkyou-amzn.asp 